\title{
Mechanistic Investigations of Ruthenium(III) Catalyzed Oxidation of L-Tryptophan by Diperiodatocuprate(III) in Aqueous Alkaline Media (Stopped Flow Technique): A Kinetic Study
}

\author{
Nagaraj P. Shetti, Ragunatharaddi R. Hosamani and Sharanappa T. Nandibewoor*
}

P.G. Department of Studies in Chemistry, Karnatak University, Dharwad-580003, India

\begin{abstract}
The kinetics of the oxidation of ruthenium(III) (Ru(III)) catalyzed oxidation of L-tryptophan (L-trp) by diperiodatocuprate(III) (DPC) in aqueous alkaline medium at a constant ionic strength of $0.20 \mathrm{~mol} \mathrm{dm}^{-3}$ was studied spectrophotometrically. The reaction between L-tryptophan and DPC in alkaline medium in presence of [Ru(III)] exhibits 1:4 stoichiometry (L-trp:DPC). The reaction was of first order in [DPC], less than unit order in [L-trp] and negative fractional order in both $\left[\mathrm{OH}^{-}\right]$and $\left[\mathrm{IO}_{4}^{-}\right]$. The order in $[\mathrm{Ru}(\mathrm{III})]$ was unity. Intervention of free radicals was observed in the reaction. The oxidation reaction in alkaline medium has been shown to proceed via a Ru(III)-L-trp complex, which reacts with monoperiodatocuprate(III) to decompose in a rate determining step followed by other fast steps to give the products. The main products were identified by spot test, IR, NMR and LC-MS. Probable mechanism is proposed and discussed. The activation parameters with respect to the slow step of the mechanism were computed and discussed and thermodynamic quantities were also calculated. The active species of catalyst and oxidant have been identified.
\end{abstract}

Keywords: Kinetics, mechanism, diperiodatocuprate (III), L-tryptophan, ruthenium(III) catalysis.

\section{INTRODUCTION}

In recent years, diperiodatocuprate(III) (DPC), is used as an oxidant in alkaline medium [1] and the oxidation studies of DPC is scanty in view of its limited solubility and stability in aqueous medium. Its use as an analytical reagent is now well recognized [2]. The Copper(III) periodate complex exhibits different multiple equilibria involving different copper(III) species in aqueous alkaline medium. It is interesting to know which of the copper(III) species is the active oxidant.

The study of the oxidation of amino acids is of interest because of their biological significance and selectivity towards the oxidants to yield different products [3-6]. Ltryptophan (L-trp) is an essential amino acid and it is needed to maintain optimum health.

In recent years, the use of transition metal ions such as osmium, ruthenium and iridium, either alone or as binary mixtures, as catalysts in various redox processes has attracted considerable interest [7]. The $\mathrm{Ru}(\mathrm{III})$ acts as a catalyst in the oxidation of many organic and inorganic substrates $[8,9]$. The catalysed mechanism can be quite complicated due to formation of different intermediate complexes, and different oxidation states of ruthenium(III). Although the mechanism of catalysis depends on the nature of the substrate, oxidant and on the experimental conditions, it has been shown [10] that metal ions act as catalysts by one of these different paths such as the formation of complexes with reactant or oxidation of the substrate itself or through

*Address correspondence to this author at the P.G. Department of Studies in Chemistry, Karnatak University, Dharwad-580003, India; Fax: 91-836274788; E-mail: stnandibewoor@yahoo.com the formation of free radicals. The uncatalysed reaction of oxidation of L-tryptophan by DPC has been studied [11]. We have observed that the micro amounts of ruthenium catalyses the oxidation of L-tryptophan by DPC in alkaline medium. In earlier reports [12] on DPC oxidation, periodate had a retarding effect and the order in alkali was found to be less than unity in most of the reactions. However in the present study we have observed entirely different kinetic observations.

In order to understand the active species of oxidant and catalyst, to compute the activity of the catalyst and to propose the appropriate mechanism, the title reaction is investigated in detail. An understanding of the mechanism allows the chemistry to be interpreted, understood and predicted.

\section{EXPERIMENTAL}

\subsection{Materials and Reagents}

All chemicals used were of reagent grade and double distilled water was used throughout the work. A solution of L-tryptophan (S.D. Fine Chem.) was prepared by dissolving an appropriate amount of recrystallised sample in double distilled water. The purity of L-tryptophan sample was checked by comparing its I.R. spectrum with literature data and with its m.p.280-283 ${ }^{\circ} \mathrm{C}$. A standard stock solution of $\mathrm{Ru}$ (III) was prepared by dissolving $\mathrm{RuCl}_{3}$ (S.D. Fine Chem.) $0.20 \mathrm{~mol} \mathrm{dm}^{-3} \mathrm{HCl}$. The concentration was determined [13] by EDTA titration. The copper(III) periodate complex was prepared [14] and standardized by a known procedure [15]. The UV-vis spectrum with maximum absorption at $415 \mathrm{~nm}$ verified the existence of copper(III) complex. Periodate solution was prepared by weighing the required amount of sample in hot water and used after 24 hours to complete the 
equilibrium. Its concentration was ascertained iodometrically [16] at neutral $\mathrm{pH}$ maintained using a phosphate buffer. $\mathrm{KOH}(\mathrm{BDH})$ and $\mathrm{KNO}_{3}(\mathrm{AR})$ were employed to maintain the required alkalinity and ionic strength respectively. The temperature was maintained constant to within $\pm 0.1^{\circ} \mathrm{C}$.

\subsection{Kinetic Measurements}

The kinetics was followed under pseudo first-order condition where [L-trp] $>$ [DPC] at $25 \pm 0.1{ }^{\circ} \mathrm{C}$, unless specified. The reaction was initiated by mixing the DPC to [L-trp] solution which also contained required concentrations of $\mathrm{Ru}(\mathrm{III}), \mathrm{KNO}_{3}, \mathrm{KOH}$ and $\mathrm{KIO}_{4}$; the progress of the reaction was followed spectrophotometrically at $415 \mathrm{~nm}$ by monitoring the decrease in absorbance due to DPC with the molar absorbancy index, ' $\varepsilon$ ' at $6235 \pm 100 \mathrm{dm}^{3} \mathrm{~mol}^{-1} \mathrm{~cm}^{-1}$ (Literature $\varepsilon=6230$ ) [14]. It was verified that there is a negligible interference from other species present in the reaction mixture at this wavelength. The pseudo-first order rate constants, ' $\mathrm{k}_{\mathrm{T}}$ ', were determined from the $\log$ (absorbance) versus time plots. The plots were linear up to $85 \%$ completion of reaction under the range of $\left[\mathrm{OH}^{-}\right]$ used. During the kinetics a constant concentration viz. $5.0 \mathrm{x}$ $10^{-4} \mathrm{~mol} \mathrm{dm}^{-3}$ of $\mathrm{KIO}_{4}$ was used throughout the study unless otherwise stated. Since the excess of periodate is present in DPC, the possibility of oxidation of L-tryptophan by periodate in an alkaline medium at $25^{\circ} \mathrm{C}$ was tested. The progress of the reaction was followed iodometrically. However, it was found that there was no significant reaction under the experimental conditions employed compared to the DPC oxidation of L-tryptophan. The total concentration of periodate and $\mathrm{OH}^{-}$was calculated by considering the amount present in the DPC solution and that additionally added. Kinetics runs were also carried out in $\mathrm{N}_{2}$ atmosphere in order to understand the effect of dissolved oxygen on the rate of reaction. No significant difference in the results was obtained under a $\mathrm{N}_{2}$ atmosphere and in the presence of air. In view of the ubiquitous contamination of carbonate in the basic medium, the effect of carbonate was also studied. Added carbonate had no effect on the reaction rates. The spectral changes during the reaction are shown in Fig. (1). It is evident from the figure that the concentration of DPC decreases at $415 \mathrm{~nm}$.

\section{RESULTS}

\subsection{Stoichiometry and Product Analysis}

Different sets of reaction mixtures containing varying ratios of DPC to L-tryptophan in presence constant amounts of $\mathrm{Ru}(\mathrm{III}), \mathrm{OH}^{-}$and $\mathrm{KNO}_{3}$ were kept for 6 hours in closed vessel under inert atmosphere. The remaining DPC concentration was estimated by spectrophotometrically at $415 \mathrm{~nm}$. The results indicate a 1:4 stoichiometry as given in Scheme $\mathbf{1}$.

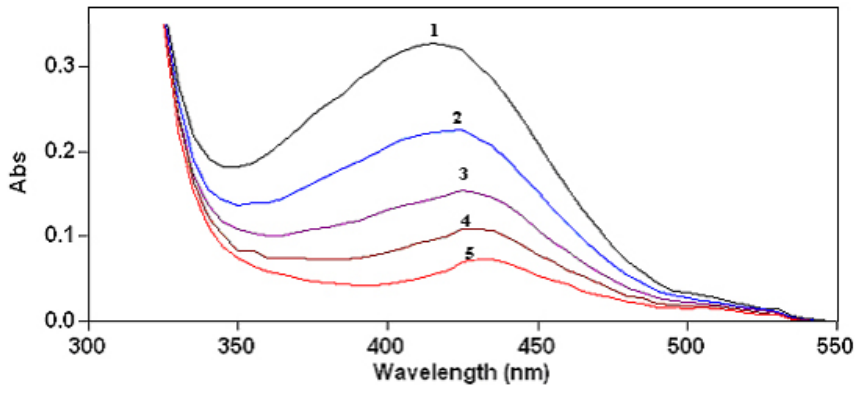

Fig. (1) Spectroscopic changes occurring in the $\mathrm{Ru}(\mathrm{III})$ catalysed oxidation of L-tryptophan by DPC at $25^{\circ} \mathrm{C},[\mathrm{DPC}]=5.0 \times 10^{-5},\left[\mathrm{OH}^{-}\right.$ ]$=0.1, \mathrm{Ru}(\mathrm{III})=8.0 \times 10^{-6}, I=0.2 \mathrm{~mol} \mathrm{dm}^{-3}$ with scanning time interval was $10 \mathrm{Sec}$.

The main product, indole-3-acetic acid was separated [17] by TLC, using the mixtures of methyl acetate, isopropanol and $25 \%$ ammonium hydroxide in the ratio of $45: 35: 20(\mathrm{v} / \mathrm{v})$. It is characterized by its melting point $\left(164^{\circ} \mathrm{C}\right)$ and IR, NMR and LC-ESI-MS spectral studies.

The IR spectrum of the product showed (Appendix Fig. 1) a sharp band at $3389 \mathrm{~cm}^{-1}$, assigned to indole $-\mathrm{NH}$ and a series of bands in the region of 2730 to $3127 \mathrm{~cm}^{-1}$ were due to the hydrogen bonded $-\mathrm{OH}$ stretching frequencies. An intense sharp band at $1701 \mathrm{~cm}^{-1}$ was due to $\mathrm{C}=\mathrm{O}$ stretching frequencies of carboxylic group. The absorbance of broad bands in the region of 3086 to $3310 \mathrm{~cm}^{-1}$ and presence of only one intense sharp band at $3389 \mathrm{~cm}^{-1}$ confirms the absence of free $\mathrm{NH}_{2}$ and presence of indole - $\mathrm{NH}$ group. The frequency bands of the product accurately matched with the literature spectrum of the indole-3-acetic acid. ${ }^{1}$ HNMR ( 300 $\mathrm{MHz}$, DMSO $\left.\mathrm{d}_{6}\right)$ spectrum showed peaks in ppm $(1 \mathrm{H}, \mathrm{s}, \delta-$ 10.88) carboxylic $\mathrm{OH}\left(\mathrm{D}_{2} \mathrm{O}\right.$ exchanged); $(2 \mathrm{Ar} \mathrm{H}, \mathrm{d}, \delta-7.49$ and 7.47); (2Ar H, t, $\delta-7.36$ and 7.33); ( $1 \mathrm{Ar} \mathrm{H}, \mathrm{s}, 6.98) ;(1 \mathrm{H}$, $\mathrm{s}, \delta$-4.48) for $\mathrm{NH}\left(\mathrm{D}_{2} \mathrm{O}\right.$ exchanged); and $(1 \mathrm{H}, \mathrm{s}, \delta-2.5)$. Where as ${ }^{13} \mathrm{CNMR}(300 \mathrm{MHz}$, DMSO d 6 ) peaks at $\delta: 174.29$, $136.88,127.94,124.75,121.97,119.39,119.33,112.25$, 108.46 and $31.82 \mathrm{ppm}$ are assigned to carbons designated with numbers 1,2, 3, 4, 5, 6, 7, 8, 9 and 10 respectively (Fig. 2). LC-ESI-MS analysis of isolated product indicated the presence of indole-3-acetic acid as molecular ion peak of $\mathrm{m} / \mathrm{z}$ $176(\mathrm{~m}+1)$ (Fig. 3). The molecular ion of L-tryptophan was $\mathrm{m} / \mathrm{z} 205(\mathrm{~m}+1)$.

The byproducts were identified as ammonia by Nessler's reagent [15] and the $\mathrm{CO}_{2}$ was qualitatively detected by bubbling nitrogen gas through the acidified reaction mixture and passing the liberated gas through tube containing limewater.

Regression analysis of experimental data to obtain the regression coefficient $\mathrm{r}$ and standard deviation $\mathrm{S}$ of point from the regression line was performed using Microsoft

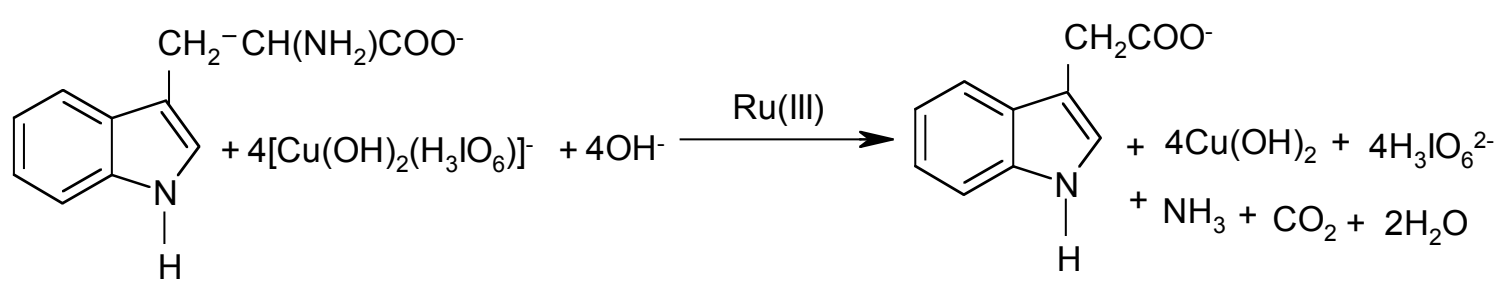

Scheme 1. 1:4 stoichiometry. 


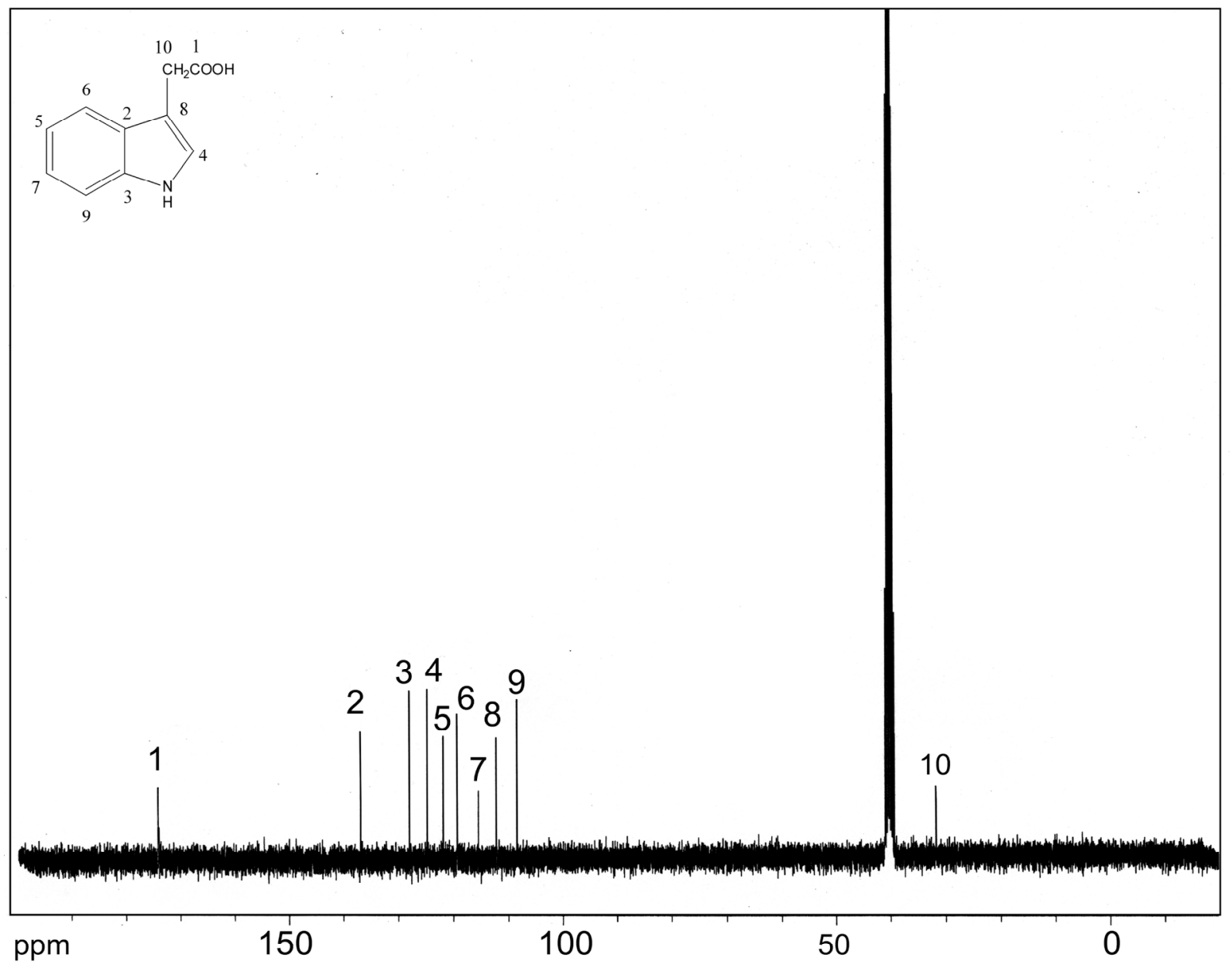

Fig. (2). ${ }^{13} \mathrm{CNMR}$ spectra of indole-3-acetic acid in DMSO $d_{6} .(1)=174.29,(2)=136.88,(3)=127.94,(4)=124.75,(5)=121.97,(6)=119.39$, $(7)=119.33,(8)=112.25,(9)=108.46,(10)=31.82$.

\section{Excel-2003 programme.}

\subsection{Reaction Order}

As the diperiodatocuprate (III) oxidation of L-tryptophan in alkaline medium proceeds with a measurable rate in the absence of ruthenium(III), the catalysed reaction is understood to occur in parallel paths with contributions from both the catalysed and uncatalysed paths. Thus, the total rate constant $\left(\mathrm{k}_{\mathrm{T}}\right)$ is equal to the sum of the rate constants of the catalysed $\left(\mathrm{k}_{\mathrm{C}}\right)$ and uncatalysed $\left(\mathrm{k}_{\mathrm{U}}\right)$ reactions, so $\mathrm{k}_{\mathrm{C}}=\mathrm{k}_{\mathrm{T}}-\mathrm{k}_{\mathrm{U}}$. Hence the reaction orders have been determined from the slopes of $\log \mathrm{k}_{\mathrm{C}}$ versus $\log$ (concentration) plots by varying the concentrations of L-tryptophan, $\mathrm{Ru}(\mathrm{III})$ and alkali in turn while keeping the others constant. The uncatalysed reaction was followed under the conditions [L-trp] $=5.0 \times 10^{-4}$; $[D P C]=5.0 \times 10^{-5} ;\left[\mathrm{OH}^{-}\right]=0.1 ; \mathrm{I}=0.20 / \mathrm{mol} \mathrm{dm}^{-3}$. The rate constant of uncatalysed reaction $\left(\mathrm{k}_{\mathrm{U}}\right)$ was obtained by the plot of $\log$ (absorbance) versus time by following the progress of the reaction spectrophotometrically at $415 \mathrm{~nm}$.

\subsection{Effect of [Diperiodatocuprate (III)]}

The DPC concentration was varied in the range of $1.0 \mathrm{x}$ $10^{-5}$ to $1.0 \times 10^{-4} \mathrm{~mol} \mathrm{dm}^{-3}$ for both the catalysts. The linearity of the plots of $\log$ (absorbance) vs time up to $85 \%$ completion of the reaction indicates a reaction order of unity in [DPC]. This is also confirmed by varying [DPC], which did not result in any change in the pseudo first-order rate constants, $k_{C}$ (Table 1).

\subsection{Effect of [L-Tryptophan]}

The L-tryptophan concentration was varied in the range $1.0 \times 10^{-4}$ to $1.0 \times 10^{-3} \mathrm{~mol} \mathrm{dm}^{-3}$ at $25^{\circ} \mathrm{C}$ while keeping other reactant concentrations and conditions constant in the presence of $\mathrm{Ru}(\mathrm{III})$ catalyst. The $\mathrm{k}_{\mathrm{C}}$ values increased with the increase in concentration of L-tryptophan, indicating an apparent less than unit order dependence on [L-trp] ( $\mathrm{r}$ $\geq 0.8763, \mathrm{~S} \leq 0.027$ ) (Table 1) under the concentrations of experiment carried.

\subsection{Effect of [Ru (III)]}

The ruthenium(III) concentration was varied from $1.0 \mathrm{x}$ $10^{-6}$ to $1.0 \times 10^{-5} \mathrm{~mol} \mathrm{dm}^{-3}$ range, at constant concentrations of diperiodatocuprate(III)], L-tryptophan, and alkali and at constant ionic strength. The order in $[\mathrm{Ru}(\mathrm{III})]$ was found to be unity (Table $\mathbf{1}$ ).

\subsection{Effect of [Alkali] and [Periodate]}

The effect of alkali on the reaction was studied at constant concentrations of L-tryptophan and diperiodatocuprate(III) (DPC) and at a constant ionic strength of $0.20 \mathrm{~mol} \mathrm{dm}^{-3}$ in the presence of the catalyst at $25{ }^{\circ} \mathrm{C}$. The rate constant decreased with increase in [alkali] 


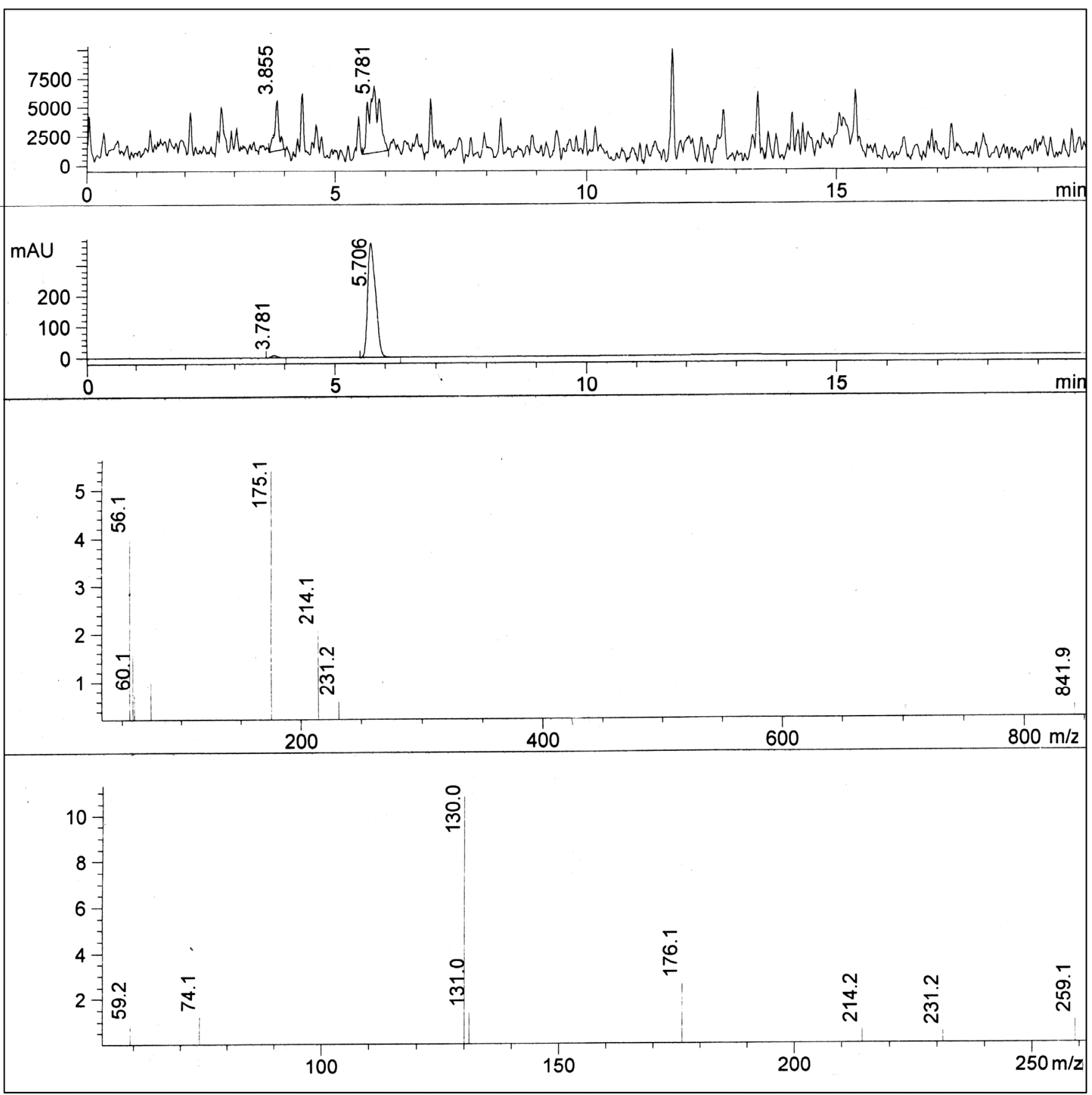

Fig. (3). LC-ESI-MS analysis of isolated product indicated the presence of Indole-3-acetic acid as molecular ion peak of $\mathrm{m} / \mathrm{z} 176(\mathrm{~m}+1)$.

indicating an apparent negative less than unit order dependence on [alkali] as given in Table $\mathbf{1}$.

The effect of $\left[\mathrm{IO}_{4}^{-}\right]$was observed by varying the concentration from $1 \times 10^{-4}$ to $1 \times 10^{-3} \mathrm{~mol} \mathrm{dm}^{-3}$ while keeping all other reactants concentrations constant. It was observed that the rate constants decreased by increasing $\left[\mathrm{IO}_{4}{ }^{-}\right]$(Table 1).

\subsection{Effect of Initially Added Products}

Initially added products, copper (II) $\left(\mathrm{CuSO}_{4}\right)$ and indole3 -acetic acid did not have any significant effect on the rate of reaction.

\subsection{Effect of Ionic Strength (I) and Dielectric Constant of the Medium (D)}

The addition of $\mathrm{KNO}_{3}$, at constant [DPC], [L-trp], $\mathrm{Ru}(\mathrm{III}),\left[\mathrm{OH}^{-}\right]$and $\left[\mathrm{IO}_{4}^{-}\right]$was found that increase in ionic strength increased the rate of reaction.

The dielectric constant of the medium, ' $\mathrm{D}$ ' was varied by varying the t-butyl alcohol and water percentage. The $D$ values were calculated from the equation $D=D_{w} V_{w}+D_{B} V_{B}$, where $D_{w}$ and $D_{B}$ are dielectric constants of pure water and tbutyl alcohol, respectively, and $\mathrm{V}_{\mathrm{w}}$ and $\mathrm{V}_{\mathrm{B}}$ are the volume fractions of components water and t-butyl alcohol, respectively, in the total mixture. The decrease in dielectric 
Table 1. Effects of [DPC], [L-trp], $\left[\mathrm{OH}^{-}\right]\left[\mathrm{IO}_{4}{ }^{-}\right]$and $[\mathrm{Ru}(\mathrm{III})]$ on the Ruthenium(III) Catalyzed Oxidation of L-Tryptophan by Diperiodatocuprate(III) in Alkaline Medium at $25^{\circ} \mathrm{C}, \mathrm{I}=0.20 \mathrm{~mol} \mathrm{dm}^{-3}$

\begin{tabular}{|c|c|c|c|c|c|c|c|c|}
\hline \multirow{2}{*}{$\begin{array}{l}{[\mathrm{DPC}] \times 10^{5}} \\
\left(\mathrm{~mol} \mathrm{dm}^{-3}\right)\end{array}$} & \multirow{2}{*}{$\begin{array}{c}{[\mathrm{L}-\operatorname{trp}] \times \mathbf{1 0}^{4}} \\
\left(\mathbf{m o l ~ d m} \mathbf{d m}^{-3}\right)\end{array}$} & \multirow{2}{*}{$\underset{\left(\mathbf{m o l ~ d m}^{-3}\right)}{\left[\mathrm{OH}^{-}\right]}$} & \multirow{2}{*}{$\begin{array}{l}{\left[\mathrm{IO}_{4}^{-}\right] \times 10^{4}} \\
\left(\mathrm{~mol} \mathrm{dm}^{-3}\right)\end{array}$} & \multirow{2}{*}{$\begin{array}{l}{[\mathrm{Ru}(\mathrm{III})] \times 10^{6}} \\
\quad\left(\mathrm{~mol} \mathrm{dm}^{-3}\right)\end{array}$} & \multirow{2}{*}{$\begin{array}{c}\mathbf{k}_{\mathrm{T}} \mathbf{x} 10^{2} \\
\left(\mathrm{~s}^{-1}\right)\end{array}$} & \multirow{2}{*}{$\begin{array}{c}\mathbf{k}_{\mathrm{U}} \times 10^{3} \\
\left(\mathrm{~s}^{-1}\right)\end{array}$} & \multicolumn{2}{|c|}{$k_{C} \times 10^{2}\left(s^{-1}\right)$} \\
\hline & & & & & & & Found & Calculated \\
\hline 3.0 & 5.0 & 0.1 & 5.0 & 8.0 & 3.41 & 5.81 & 2.83 & 2.95 \\
\hline 5.0 & 5.0 & 0.1 & 5.0 & 8.0 & 3.48 & 5.70 & 2.91 & 2.95 \\
\hline 5.0 & 1.0 & 0.1 & 5.0 & 8.0 & 1.35 & 1.34 & 1.22 & 1.17 \\
\hline 5.0 & 3.0 & 0.1 & 5.0 & 8.0 & 2.79 & 3.80 & 2.49 & 2.34 \\
\hline 5.0 & 5.0 & 0.1 & 5.0 & 8.0 & 3.48 & 5.70 & 2.91 & 2.95 \\
\hline 5.0 & 7.0 & 0.1 & 5.0 & 8.0 & 4.05 & 6.83 & 3.41 & 3.33 \\
\hline 5.0 & 10 & 0.1 & 5.0 & 8.0 & 4.71 & 8.82 & 3.83 & 3.67 \\
\hline 5.0 & 5.0 & 0.2 & 5.0 & 8.0 & 2.88 & 4.45 & 2.43 & 2.43 \\
\hline 5.0 & 5.0 & 0.1 & 1.0 & 8.0 & 4.90 & 11.44 & 3.75 & 4.00 \\
\hline 5.0 & 5.0 & 0.1 & 3.0 & 8.0 & 4.15 & 8.06 & 3.33 & 3.34 \\
\hline 5.0 & 5.0 & 0.1 & 5.0 & 8.0 & 3.48 & 5.70 & 2.91 & 2.95 \\
\hline 5.0 & 5.0 & 0.1 & 7.0 & 8.0 & 2.87 & 4.83 & 2.39 & 2.54 \\
\hline 5.0 & 5.0 & 0.1 & 10.0 & 8.0 & 2.31 & 3.72 & 1.94 & 2.02 \\
\hline 5.0 & 5.0 & 0.1 & 5.0 & 1.0 & 1.36 & 5.70 & 0.80 & 0.76 \\
\hline 5.0 & 5.0 & 0.1 & 5.0 & 3.0 & 1.71 & 5.70 & 1.14 & 1.09 \\
\hline 5.0 & 5.0 & 0.1 & 5.0 & 5.0 & 2.49 & 5.70 & 1.92 & 1.86 \\
\hline 5.0 & 5.0 & 0.1 & 5.0 & 8.0 & 3.48 & 5.70 & 2.91 & 2.95 \\
\hline
\end{tabular}

constant of the reaction medium increased the rate of the reaction. Under our experimental conditions, t-butyl alcoholwater mixture solvent did not undergo oxidation by DPC.

\subsection{Effect of Temperature (T)}

The influence of temperature on the $k_{C}$ values was studied at $15,20,25$ and $30^{\circ} \mathrm{C}$. The rate constants, $k$, of the slow step in the mechanism was obtained from the intercept of $[\mathrm{Ru}(\mathrm{III})] / k_{C}$ versus $1 /[\mathrm{L}$-trp] plots at four different temperatures. The values are given in Table 2 . The activation parameters for the rate-determining step were obtained by the least square method of plot of $\log \mathrm{k}$ versus $1 / \mathrm{T}$ and are presented in Table 2.

\subsection{Test for Free Radicals}

The intervention of free radicals was examined as follows; the reaction mixture, to which a known quantity of acrylonitrile monomer had been added initially, was kept in an inert atmosphere for 2 hours. On diluting the reaction mixture with methanol, a white precipitate was formed, indicating the intervention of free radicals in the reaction. The blank experiments of either DPC or L-tryptophan alone with acrylonitrile did not induce any polymerization under the same conditions as those induced for reaction mixture. Initially, added acrylonitrile decreased the rate of reaction indicating free radical intervention, which is the case in earlier work [18].

\subsection{Catalytic Activity}

It has been pointed out by Moelwyn- Hughes [19] that, in the presence of the catalyst, the uncatalysed and catalysed reactions proceed simultaneously, so that

$k_{T}=k_{U}+\mathrm{K}_{\mathrm{C}}\left[\right.$ catalyst ${ }^{\mathrm{x}}$

Here $\mathrm{k}_{\mathrm{T}}$ is the observed pseudo first-order rate constant in the presence of $\mathrm{Ru}(\mathrm{III})$ catalyst, $\mathrm{k}_{\mathrm{U}}$ is the pseudo first-order rate constant for the uncatalysed reaction, $K_{C}$ is the catalytic constant and ' $\mathrm{x}$ ' is the order of the reaction with respect to $[\mathrm{Ru}(\mathrm{III})]$. In the present investigation, $\mathrm{x}$ value for the standard run was found to be 1.0. Then the value of $K_{C}$ can be calculated using the equation

$$
K_{C}=\frac{k_{T}-k_{U}}{\text { [Catalyst }]^{\mathrm{x}}}=\frac{k_{C}}{[\text { Catalyst }]^{\mathrm{x}}}
$$

where, $k_{T}-k_{U}=k_{C}$

The values of $K_{C} \times 10^{-3}$ were obtained as $1.9,2.9,3.7$ and 5.1 at $288,293,298$ and $303 \mathrm{~K}$ temperatures respectively. Further, plots of $\log K_{C}$ versus $1 / \mathrm{T}$ were linear and the values of energy of activation and other activation parameters with 
Table 2. Thermodynamic Activation Parameters for the Ruthenium(III)-Catalyzed Oxidation of LTryptophan by DPC in Aqueous Alkaline Medium with Respect to The Slow Step of Scheme 2

(A) Effect of Temperature

\begin{tabular}{|c|c|}
\hline Parameters & Values \\
\hline \hline $\mathrm{Ea}\left(\mathrm{kJ} \mathrm{mol}^{-1}\right)$ & $38.5 \pm 1.8$ \\
\hline$\Delta \mathrm{H}^{\#}\left(\mathrm{~kJ} \mathrm{~mol}^{-1}\right)$ & $36 \pm 2$ \\
\hline$\Delta \mathrm{S}^{\#}\left(\mathrm{JK}^{-1} \mathrm{~mol}^{-1}\right)$ & $-51.4 \pm 3.0$ \\
\hline$\Delta \mathrm{G}^{\#}\left(\mathrm{~kJ} \mathrm{~mol}^{-1}\right)$ & $51.4 \pm 3.0$ \\
\hline $\log \mathrm{A}$ & $10.5 \pm 0.5$ \\
\hline
\end{tabular}

(B)

Activation Parameters (Scheme 2)

\begin{tabular}{|c|c|}
\hline Temperature (K) & $\mathbf{k} \mathbf{x} \mathbf{1 0}^{-3}\left(\mathbf{d m}^{3} \mathbf{~ m o l}^{-1} \mathbf{s}^{-\mathbf{1}}\right)$ \\
\hline \hline 288 & 4.24 \\
\hline 293 & 5.10 \\
\hline 298 & 6.06 \\
\hline 303 & 9.73 \\
\hline
\end{tabular}

(C)

Effect of Temperature in Calculating $K_{4}, K_{5}$ and $K_{6}$ for the $R u(I I I)$ Catalyzed Oxidation of LTryptophan by Diperiodatocuprate (III) in Alkaline Medium

\begin{tabular}{|c|c|c|c|}
\hline Temperature (K) & $\begin{array}{c}\boldsymbol{K}_{4} \mathbf{x} \mathbf{~ 1 0}^{\mathbf{2}} \\
\left(\mathbf{m o l ~ d m}^{-3}\right)\end{array}$ & $\begin{array}{c}\boldsymbol{K}_{\mathbf{5}} \mathbf{x} \mathbf{~ 1 0}^{4} \\
\left(\mathbf{m o l ~ d m}^{-3}\right)\end{array}$ & $\begin{array}{c}\boldsymbol{K}_{6} \mathbf{x} \mathbf{~ 1 0}^{-4} \\
\left.\mathbf{( d m}^{\mathbf{3}} \mathbf{~ m o l}^{-\mathbf{1}}\right)\end{array}$ \\
\hline \hline 288 & $13.3 \pm 0.3$ & $0.38 \pm 0.01$ & $4.32 \pm 0.1$ \\
\hline 293 & $8.6 \pm 0.2$ & $0.92 \pm 0.02$ & $3.69 \pm 0.08$ \\
\hline 298 & $6.1 \pm 0.2$ & $1.68 \pm 0.04$ & $2.78 \pm 0.05$ \\
\hline 303 & $4.7 \pm 0.1$ & $1.2 \pm 0.03$ & $1.99 \pm 0.04$ \\
\hline
\end{tabular}

(D) Thermodynamic Quantities Using $K_{4}, K_{5}$ and $K_{6}$

\begin{tabular}{|c|c|c|c|}
\hline $\begin{array}{c}\text { Thermodynamic } \\
\text { Quantities }\end{array}$ & $\begin{array}{c}\text { Values f } \\
\text { rom } \boldsymbol{K}_{4}\end{array}$ & $\begin{array}{c}\text { Values } \\
\text { from } \boldsymbol{K}_{5}\end{array}$ & $\begin{array}{c}\text { Values } \\
\text { from } \boldsymbol{K}_{6}\end{array}$ \\
\hline \hline$\Delta \mathrm{H}\left(\mathrm{k} \mathrm{J} \mathrm{mol}^{-1}\right)$ & $-51 \pm 1$ & $81.0 \pm 0.2$ & $-38.0 \pm 0.8$ \\
\hline$\Delta \mathrm{S}_{\left(\mathrm{J} \mathrm{K}^{-1} \mathrm{~mol}^{-1}\right)}$ & $-192 \pm 4$ & $198 \pm 4$ & $-42 \pm 1$ \\
\hline$\Delta \mathrm{G}_{298}\left(\mathrm{k} \mathrm{J} \mathrm{mol}^{-1}\right)$ & $6.4 \pm 0.1$ & $22.1 \pm 0.5$ & $-25.3 \pm 0.5$ \\
\hline
\end{tabular}

reference to catalyst were computed as $\mathrm{Ea}\left(\mathrm{kJ} \mathrm{mol}^{-1}\right)=44.9$, $\Delta \mathrm{H}^{\#}\left(\mathrm{~kJ} \mathrm{~mol}^{-1}\right)=42.4, \Delta \mathrm{S}^{\#}\left(\mathrm{JK}^{-1} \mathrm{~mol}^{-1}\right)=-34.2, \Delta \mathrm{G}^{\#}\left(\mathrm{~kJ} \mathrm{~mol}^{-1}\right)$ $=53.1, \log \mathrm{A}=11.4$.

\section{DISCUSSION}

The water-soluble copper(III) periodate complex is reported [20] to be $\left[\mathrm{Cu}\left(\mathrm{HIO}_{6}\right)_{2}(\mathrm{OH})_{2}\right]^{7-}$. However, in an aqueous alkaline medium and at a high $\mathrm{pH}$ range employed in the study, periodate is unlikely to exist as $\mathrm{HIO}_{6}{ }^{4-}$ (as present in the complex) as is evident from its involvement in the multiple equilibria [21] (3)-(5), depending on the $\mathrm{pH}$ of the solution.

$$
\begin{array}{ll}
\mathrm{H}_{5} \mathrm{IO}_{6} \stackrel{\mathrm{K}_{1}}{\rightleftharpoons} \mathrm{H}_{4} \mathrm{IO}_{6}^{-}+\mathrm{H}^{+} & \mathrm{K}_{1}=5.1 \times 10^{-4} \\
\mathrm{H}_{4} \mathrm{IO}_{6}^{-}=\mathrm{K}_{3} \mathrm{H}_{6} \mathrm{IO}_{6}^{2-}+\mathrm{H}^{+} & \mathrm{K}_{2}=4.9 \times 10^{-9} \\
\mathrm{H}_{3} \mathrm{IO}_{6}{ }^{2-}=\stackrel{\mathrm{K}_{3}}{=} \mathrm{H}_{2} \mathrm{IO}_{6}{ }^{3-}+\mathrm{H}^{+} & \mathrm{K}_{3}=2.5 \times 10^{-12}
\end{array}
$$

Periodic acid exists as $\mathrm{H}_{5} \mathrm{IO}_{6}$ in acid medium and as $\mathrm{H}_{4} \mathrm{IO}_{6}^{-}$near $\mathrm{pH}$ 7. Hence, under alkaline conditions as employed in this study, the main species are expected to be $\mathrm{H}_{3} \mathrm{IO}_{6}{ }^{2-}$ and $\mathrm{H}_{2} \mathrm{IO}_{6}{ }^{3-}$. Thus, at the $\mathrm{pH}$ employed in this study, the soluble copper (III) periodate complex might be $\left[\mathrm{Cu}(\mathrm{OH})_{2}\left(\mathrm{H}_{3} \mathrm{IO}_{6}\right)_{2}\right]^{3-}$, a conclusion also supported by earlier work $[22,23]$.

$\mathrm{Ru}(\mathrm{III})$ chloride acts as an efficient catalyst in many redox reactions, particularly in an alkaline medium [18,24]. It is interesting to identify the probable ruthenium(III) chloride species in alkaline media. In the present study it is quite probable that the $\left[\mathrm{Ru}\left(\mathrm{H}_{2} \mathrm{O}\right)_{5} \mathrm{OH}\right]^{2+}$ species might assume the general form $\left[\mathrm{Ru}(\mathrm{III})(\mathrm{OH})_{\mathrm{x}}\right]^{3-\mathrm{x}}$. The $\mathrm{x}$ value would always be less than six because there are no definite reports of any hexahydroxy ruthenium species. The remainder of the coordination sphere would be filled by water molecules. Hence, under the conditions employed, e.g. $\left[\mathrm{OH}^{-}\right]>>[\mathrm{Ru}(\mathrm{III})]$, ruthenium(III) is mostly present as the hydroxylated species, $\left[\mathrm{Ru}\left(\mathrm{H}_{2} \mathrm{O}\right)_{5} \mathrm{OH}\right]^{2+}$. Similar equilibria have been reported between $\mathrm{Ru}(\mathrm{III})$ catalysed oxidation of several other substrates with various oxidants in alkaline medium [25].

The reaction between the $\mathrm{Ru}(\mathrm{III})$ catalysed oxidation of L-tryptophan by diperiodatocuprate(III) complex in alkaline medium has the stoichiometry 1:4 (L-trp: DPC) with a first order dependence on both [DPC] and [Ru(III)] and an apparent order of less than unity in [substrate], a negative fractional order dependence both on the [periodate] and [alkali]. No effect of added products was observed. Based on the experimental results, a mechanism is proposed for which all the observed orders in each constituent such as [catalyst], [oxidant], [reductant], [OH'] and $\left[\mathrm{IO}_{4}^{-}\right]$may be well accommodated. It is known that L-tryptophan exists in the form of Zwitterion [26] in aqueous medium. In highly acidic medium, it exists in the protonated form, where as in highly basic medium it is in the fully deprotonated form [26].

In most of the reports [12] on Ru(III) catalysed DPC oxidation, periodate had a retarding effect and $\mathrm{OH}^{-}$had an increasing effect on the rate of the reaction. However in the present kinetic study, different kinetic results have been obtained. In this study both $\mathrm{OH}^{-}$and periodate retarded the rate of the reaction. The result of decrease in rate of reaction with increase in alkalinity (Table 1) can be explained in terms of prevailing equilibrium of formation of $\left[\mathrm{Cu}(\mathrm{OH})_{2}\left(\mathrm{H}_{3} \mathrm{IO}_{6}\right)\right]^{3-}$ from $\left[\mathrm{Cu}(\mathrm{OH})_{2}\left(\mathrm{H}_{3} \mathrm{IO}_{6}\right)\left(\mathrm{H}_{2} \mathrm{IO}_{6}\right)\right]^{4-}$ hydrolysis as given in the following Equation.(6).

$\left[\mathrm{Cu}(\mathrm{OH})_{2}\left(\mathrm{H}_{3} \mathrm{O}_{6}\right)\left(\mathrm{H}_{2} \mathrm{IO}_{6}\right)\right]^{4-}+\mathrm{H}_{2} \mathrm{O}=\mathrm{K}_{4}=\left[\mathrm{Cu}(\mathrm{OH})_{2}\left(\mathrm{H}_{3} \mathrm{IO}_{6}\right)\right]^{3-}+\mathrm{OH}^{-}$

Also decrease in rate with increase in $\left[\mathrm{H}_{3} \mathrm{IO}_{6}{ }^{2-}\right]$ (Table 1) suggest that equilibrium of copper(III) periodate complex to 
form monoperiodatocuptrate(III) (MPC) species as given in Equation (7) is established.

$\left[\mathrm{Cu}(\mathrm{OH})_{2}\left(\mathrm{H}_{3} \mathrm{IO}\right)_{2}\right]^{3-}=\left[\mathrm{K}{ }^{\mathrm{K}} \longrightarrow[\mathrm{OH})_{2}\left(\mathrm{H}_{3} \mathrm{IO}\right)\right]^{-}+\mathrm{H}_{3} \mathrm{IO}_{6}{ }^{2-}$

Such type of equilibria (6) and (7) have been well noticed in literature [11,12]. It may be expected that a lower periodate complex such as monoperiodatocuptrate(III) (MPC) is more important in the reaction than the DPC. The inverse fractional order in $\left[\mathrm{H}_{3} \mathrm{IO}_{6}{ }^{2-}\right]$ might also be due to this reason. Therefore, MPC might be the main reactive form of the oxidant.

The less than unit order in [L-trp] presumably results from formation of a complex (C) between the ruthenium(III) species and L-trp prior to the formation of the products. This complex (C) reacts with one mole of MPC in a slow step to give the intermediate species of free radical derived from Ltryptophan, $\mathrm{Cu}(\mathrm{II})$ spices with regeneration of catalyst, ruthenium(III). This free radical spices further reacts with another molecule of MPC in a fast step to form indole-3acetal intermediate. The indole-3-acetal then reacts with two more molecules of MPC in a further fast step to form the products such as indole-3-acetic acid, $\mathrm{Cu}(\mathrm{II})$ and periodate as given in Scheme 2.

The probable structure of the complex (C) is given in Scheme 3. and it shows that the carbonyl group oxygen was coordinated to the metal complex.
Since Scheme $\mathbf{2}$ is in accordance with the generally wellaccepted principle of non-complementary oxidations taking place in sequence of one-electron steps, the reaction between the substrate and oxidant would afford a radical intermediate. A free radical scavenging experiment revealed such a possibility (see infra). This type of radical intermediate has also been observed in earlier work [11]. Spectroscopic evidence for the complex formation between Ruthenium(III) and L-tryptophan was obtained from UV-Vis spectra of L-tryptophan $\left(5.0 \times 10^{-4}\right), \mathrm{Ru}(\mathrm{III})\left(8.0 \times 10^{-6}, \mathrm{OH}^{-}\right.$ ] $\left.=0.1 \mathrm{~mol} \mathrm{dm}^{-3}\right)$ and a mixture of both. A bathochromic shift of about $8 \mathrm{~nm}$ from $273 \mathrm{~nm}$ to $281 \mathrm{~nm}$ in the spectra of L-tryptophan was observed. However, the Michaelis-Menten plot also proved the complex formation between catalyst and reductant, which explains the less than unit order dependence on [L-trp]. Such type of complex between a substrate and a catalyst has been observed in other studies [27].

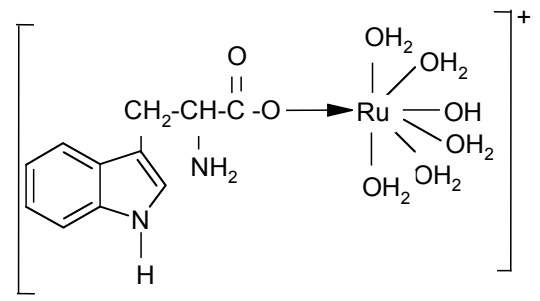

Scheme 3. The probable structure of the ruthenium(III) and Ltryptophan complex.
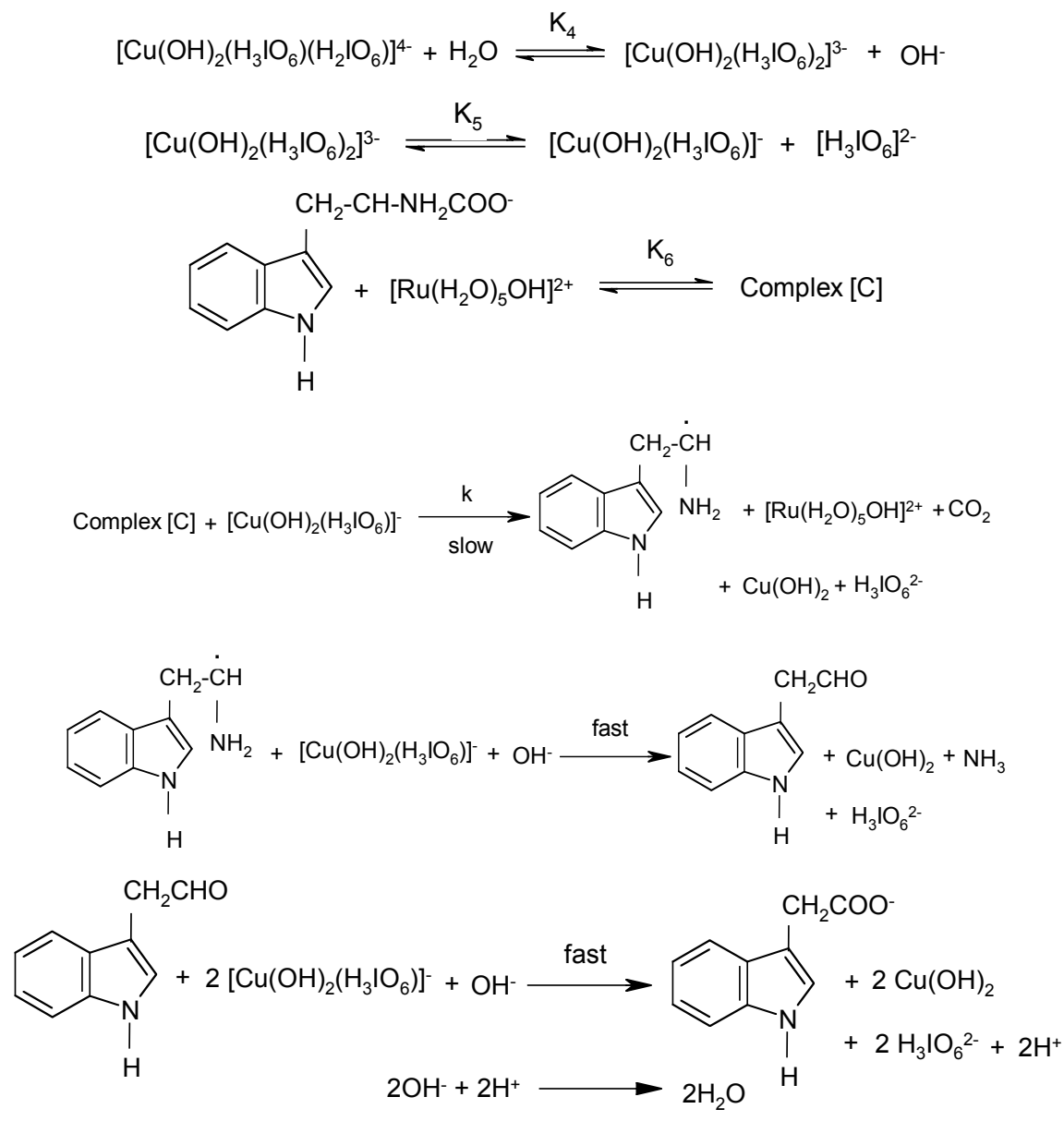

Scheme 2. Detailed Scheme for the oxidation of ruthenium(III) catalysed oxidation of L-tryptophan by diperiodatocuprate(III). 
The rate law (8) for Scheme $\mathbf{2}$ could be derived as

$$
\begin{aligned}
\text { rate }=\frac{-\mathrm{d}[\mathrm{DPC}]}{\mathrm{dt}}= & \frac{\mathrm{kK}_{4} \mathrm{~K}_{5} \mathrm{~K}_{6}[\mathrm{Cu}(\mathrm{III})][\mathrm{L}-\operatorname{trp}][\mathrm{Ru}(\mathrm{III})]}{\left[\mathrm{H}_{3} \mathrm{IO}_{6}{ }^{2-}\right][\mathrm{OH}]+\mathrm{K}_{4}\left[\mathrm{OH}^{-}\right]\left[\mathrm{H}_{3} \mathrm{IO}_{6}{ }^{2}\right]+\mathrm{K}_{4} \mathrm{~K}_{5}+\mathrm{K}_{4} \mathrm{~K}_{5} \mathrm{~K}_{6}[\mathrm{~L}-\operatorname{trp}]} \\
& +\mathrm{K}_{6}\left[\mathrm{H}_{3} \mathrm{IO}_{6}{ }^{2-}\right][\mathrm{L}-\mathrm{trp}]\left[\mathrm{OH}^{-}\right]+\mathrm{K}_{4} \mathrm{~K}_{6}[\mathrm{~L}-\operatorname{trp}]\left[\mathrm{H}_{3} \mathrm{IO}_{6}{ }^{2}{ }^{2}\right]
\end{aligned}
$$

The terms $\left(\mathrm{K}_{6}\left[\mathrm{H}_{3} \mathrm{IO}_{6}{ }^{2-}\right]\left[\mathrm{OH}^{-}\right]\right.$[L-trp] $)$and $\left(\mathrm{K}_{4} \mathrm{~K}_{6}\right.$ [L-trp] [ $\left.\mathrm{H}_{3} \mathrm{IO}_{6}{ }^{2-}\right]$ ) of denominator of equation (8) can be neglected as compared with higher values of other terms in the denominator in the view of low concentrations of Ltryptophan and periodate used in the study. Therefore, equation (8) becomes

Rate

$\underline{\mathrm{Rate}}=\mathrm{k}_{\mathrm{C}}=\mathrm{k}_{\mathrm{T}}-\mathrm{k}_{\mathrm{U}}$

[DPC]

$$
=\frac{\mathrm{kK}_{4} \mathrm{~K}_{5} \mathrm{~K}_{6}[\mathrm{~L}-\mathrm{trp}][\mathrm{Ru}(\mathrm{III})]}{\left[\mathrm{H}_{3} \mathrm{IO}_{6}{ }^{2-}\right]\left[\mathrm{OH}^{-}\right]+\mathrm{K}_{4}\left[\mathrm{H}_{3} \mathrm{IO}_{6}{ }^{2-}\right]+\mathrm{K}_{4} \mathrm{~K}_{5}+\mathrm{K}_{4} \mathrm{~K}_{5} \mathrm{~K}_{6}[\mathrm{~L}-\operatorname{trp}]}
$$

which explains all the observed kinetic orders of different species. The rate law (9) can be rearranged into the following form suitable for verification.

$\frac{[\mathrm{Ru}(\mathrm{III})]}{\mathrm{k}_{\mathrm{c}}}=\frac{\left[\mathrm{H}_{3} \mathrm{OO}_{6}{ }^{2-}\right][\mathrm{OH}-]}{\mathrm{kK}_{4} \mathrm{~K}_{5} \mathrm{~K}_{6}[\mathrm{~L}-\mathrm{tr} p]}+\frac{\left[\mathrm{H}_{3} \mathrm{OO}_{6}{ }^{2-}\right]}{\mathrm{kK}_{5} \mathrm{~K}_{6}[\mathrm{~L}-\mathrm{trp}]}+\frac{1}{k K_{6}[\mathrm{~L}-\mathrm{tr} p]}+\frac{1}{\mathrm{k}}$

The plots of $[\mathrm{Ru}(\mathrm{III})] / \mathrm{k}_{\mathrm{C}}$ versus $\left[\mathrm{H}_{3} \mathrm{IO}_{6}{ }^{2-}\right],[\mathrm{Ru}(\mathrm{III})] / \mathrm{k}_{\mathrm{C}}$ versus $\left[\mathrm{OH}^{-}\right]$and $[\mathrm{Ru}(\mathrm{III})] / \mathrm{k}_{\mathrm{C}}$ versus $1 /[\mathrm{L}$-trp] were linear with an intercept supporting the $\mathrm{Ru}(\mathrm{III})$ and L-tryptophan complex which is verified in Fig. (4). From the intercepts and slopes of such plots, the reaction constants $\mathrm{K}_{4}, \mathrm{~K}_{5}, \mathrm{~K}_{6}$ and $\mathrm{k}$ were calculated as $(6.1 \pm 0.2) \times 10^{-2} \mathrm{~mol} \mathrm{dm}^{-3},(1.68 \pm$ $0.4) \times 10^{-4} \mathrm{~mol} \mathrm{dm}^{-3},(2.78 \pm 0.05) \times 10^{4} \mathrm{dm}^{3} \mathrm{~mol}^{-1},(6.06 \pm$ $0.04) \times 10^{3} \mathrm{dm}^{3} \mathrm{~mol}^{-1} \mathrm{~s}^{-1}$ respectively. The values of $\mathrm{K}_{4}$ and $\mathrm{K}_{5}$ obtained are in good agreement with previously reported work [11]. These constants were used to calculate the rate constants over different experimental conditions, when compared with the experimental $\mathrm{k}_{\mathrm{C}}$ values, they are found to be in reasonable agreement with each other, which fortifies the Scheme 2. The effect of ionic strength and dielectric constant of the medium on the rate explains quantitatively the reaction between two oppositely charged ions as seen in Scheme 2.

The thermodynamic quantities for the different equilibrium steps in Scheme $\mathbf{2}$ can be evaluated as follows. The L-tryptophan and hydroxide ion concentrations (Table 1) were varied at different temperatures. The plots of $[\mathrm{Ru}(\mathrm{III})] / \mathrm{k}_{\mathrm{C}}$ versus $1 /[\mathrm{L}-\operatorname{trp}](\mathrm{r} \geq 0.9984, \mathrm{~S} \leq 0.00131)$ and $[\mathrm{Ru}(\mathrm{III})] / \mathrm{k}_{\mathrm{c}}$ versus $\left[\mathrm{OH}^{-}\right](\mathrm{r} \geq 0.9811, \mathrm{~S} \leq 0.00097)$ should be linear, as shown in Fig. (4). From the slopes and intercepts, the values of $\mathrm{K}_{4}$ are calculated at different temperatures. A van't Hoff's plot was made for the variation of $\mathrm{K}_{4}$ with temperature [i.e., $\log \mathrm{K}_{4}$ versus $1 / \mathrm{T}(\mathrm{r} \geq 0.9874, \mathrm{~S} \leq 0.1107)$ ] and the values of the enthalpy of reaction $\Delta \mathrm{H}$, entropy of reaction $\Delta \mathrm{S}$ and free energy of reaction $\Delta \mathrm{G}$, were calculated. These values are also given in Table 2. A comparison of $\Delta \mathrm{H}$ value $(81.0 \pm 0.2)$ from $\mathrm{K}_{5}$ with that of $\Delta \mathrm{H}^{\#}(36 \pm 2)$ of rate limiting step supports that the second step of Scheme $\mathbf{2}$ is fairly slow since it involves high activation energy [28]. In the same manner, $\mathrm{K}_{4}$ and $\mathrm{K}_{6}$ values were calculated at different temperatures and the corresponding values of the thermodynamic quantities are given in Table $\mathbf{2}$.

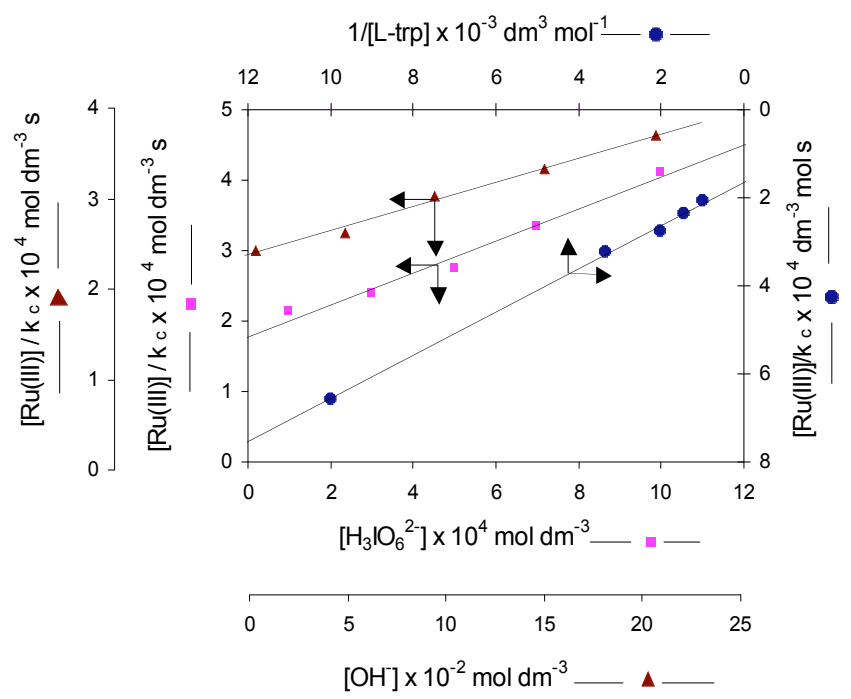

Fig. (4). Verification of rate law (9) for the $\mathrm{Ru}(\mathrm{III})$ catalysed oxidation of L-tryptophan by DPC at $25^{\circ} \mathrm{C}$ (Conditions as given in Table 1).

The values of $\Delta H^{\#}$ and $\Delta S^{\#}$ were both favorable for electron transfer processes. The favorable enthalpy was due to release of energy on solutions changes in the transition state. The negative value of $\Delta S^{\#}$ suggests that the intermediate complex is more ordered than the reactants [29]. The observed modest enthalpy of activation and a higher rate constant for the slow step indicates that the oxidation presumably occurs via an inner-sphere mechanism. This conclusion is supported by earlier observations [30,31]. The activation parameters evaluated for the catalysed and uncatalysed reaction explain the catalytic effect on the reaction. The catalyst $\mathrm{Ru}(\mathrm{III})$ forms the complex (C) with the substrate, which enhances the reducing property of the substrate than that without the $\mathrm{Ru}(\mathrm{III})$ catalyst. Further, the $\mathrm{Ru}$ (III) catalyst modifies the reaction path by lowering the energy of activation.

\section{CONCLUSION}

The $\mathrm{Ru}(\mathrm{III})$ catalysed oxidation of L-tryptophan by diperiodatocuprate(III) was studied. Oxidation products were identified. Among various species of $\mathrm{Cu}(\mathrm{III})$ in alkaline medium, monoperiodatocuprate(III) is considered to be the active species for the title reaction. The active species of $\mathrm{Ru}(\mathrm{III})$ was found to be $\left[\mathrm{Ru}\left(\mathrm{H}_{2} \mathrm{O}\right)_{5} \mathrm{OH}\right]^{2+}$. Activation parameters were evaluated for both catalyzed and uncatalysed reactions and compared. Catalytic constants and the activation parameters with reference to the catalyst were also computed.

\section{ACKNOWLEDGEMENTS}

One of the authors, N.P.S. thanks Dr. S.K. Nataraj, Research Scientist, Chonnam National University, Gwangju, Republic of Korea and Dr. Shivanand Teli, Post Doctoral Research Associate, Hanyang University, Seoul, Republic of Korea, for their kind help to do the present research work. 


\section{APPENDIX}

According to Scheme 2,

Rate $=\frac{-\mathrm{d}[\mathrm{DPC}]}{\mathrm{dt}}=\mathrm{k}[\mathrm{C}]\left[\mathrm{Cu}^{-}\right]=\frac{\mathrm{kK}_{4} \mathrm{~K}_{5} \mathrm{~K}_{6}[\mathrm{~L}-\operatorname{trp}][\mathrm{Ru}(\mathrm{IIII})]\left[\mathrm{Cu}^{4-}\right]}{\left[\mathrm{OH}^{-}\right]\left[\mathrm{H}_{3} \mathrm{IO}_{6}{ }^{2-}\right]}$

$[D P C]_{T}=\left[\mathrm{Cu}^{3}\right]_{\mathrm{f}}+\left[\mathrm{Cu}^{4-}\right]_{\mathrm{f}}+\left[\mathrm{Cu}^{-}\right]_{\mathrm{f}}$

where $\left[\mathrm{Cu}^{3}\right]=\left[\mathrm{Cu}(\mathrm{OH})_{2}\left(\mathrm{H}_{3} \mathrm{OO}_{6}\right)_{2}\right]^{3-},\left[\mathrm{Cu}^{4-}\right]=\left[\mathrm{Cu}(\mathrm{OH})_{2}\left(\mathrm{H}_{3} \mathrm{IO}_{6}\right)\left(\mathrm{H}_{2} \mathrm{IO}_{6}\right)\right]^{4-},[\mathrm{Cu}-]=\left[\mathrm{Cu}(\mathrm{OH})_{2}\left(\mathrm{H}_{3} \mathrm{IO}_{6}\right)\right]$

$\mathrm{T}$ and $\mathrm{f}$ refer to total and free concentrations.

$[D P C]_{T}=\left[\mathrm{Cu}^{4-}\right]\left[1+\frac{\mathrm{K}_{5}}{\left[\mathrm{OH}^{-}\right]}+\frac{\mathrm{K}_{5} \mathrm{~K}_{6}}{\left[\mathrm{H}_{2} \mathrm{IO}_{6}\right]^{3-}\left[\mathrm{OH}^{-}\right]}\right]$

$[\mathrm{DPC}]_{\mathrm{T}}\left[\mathrm{H}_{3} \mathrm{IO}_{6}\right]^{2-}\left[\mathrm{OH}^{-}\right]$

$\left[\mathrm{Cu}^{4-}\right]=\frac{}{\left[\mathrm{H}_{3} \mathrm{OO}_{6}{ }^{2-}\right]+\left[\mathrm{OH}^{-}\right]+\mathrm{K}_{4}\left[\mathrm{H}_{3} \mathrm{IO}_{6}{ }^{2-}\right]+\mathrm{K}_{4} \mathrm{~K}_{5}}$

Similarly,

$\mathrm{Ru}(\mathrm{IIII})_{\mathrm{T}}=\mathrm{Ru}(\mathrm{III})_{\mathrm{f}}+[\mathrm{C}]=\mathrm{Ru}(\mathrm{III})_{\mathrm{f}}+\mathrm{K}_{6}[\mathrm{~L}-\operatorname{trp}]\left[\mathrm{Ru}(\mathrm{III})_{\mathrm{f}}\right.$

$\mathrm{Ru}(\mathrm{III})_{\mathrm{f}}=\frac{\mathrm{Ru}(\mathrm{III})_{\mathrm{T}}}{\left(1+\mathrm{K}_{6}[\mathrm{~L}-\mathrm{trp}]\right)} \quad(\mathrm{III})$ Similarly, $[\mathrm{L}-\mathrm{trp}]_{\mathrm{f}}=\frac{[\mathrm{L}-\mathrm{trp}]_{\mathrm{T}}}{\left[1+\mathrm{K}_{6} \mathrm{Ru}(\mathrm{III})\right]}$

In eqn.(IV) low concentrations of $\mathrm{Ru}$ (III) used, so the term $\left[1+\mathrm{K}_{6} \mathrm{Ru}(\mathrm{III})\right]$ is neglected

Therefore, $[\mathrm{L}-\mathrm{trp}]_{\mathrm{T}}=[\mathrm{L}-\mathrm{trp}]_{\mathrm{f}}$ similarly, $\left[\mathrm{OH}^{-}\right]_{\mathrm{T}}=\left[\mathrm{OH}^{-}\right]_{\mathrm{f}}$

Rate $=\frac{-\mathrm{d}[\mathrm{DPC}]}{\mathrm{dt}}=\frac{\mathrm{k} \mathrm{K}_{4} \mathrm{~K}_{5} \mathrm{~K}_{6}[\mathrm{~L}-\mathrm{trp}][\mathrm{Ru}(\mathrm{III})]}{\left[\mathrm{H}_{3} \mathrm{OO}_{6}{ }^{2-}\right][\mathrm{OH}-]+\mathrm{K}_{4}\left[\mathrm{H}_{3} \mathrm{O}_{6}{ }^{2-}\right]+\mathrm{K}_{4} \mathrm{~K}_{5}+\mathrm{K}_{4} \mathrm{~K}_{5} \mathrm{~K}_{6}[\mathrm{~L}-\operatorname{trp}]}$

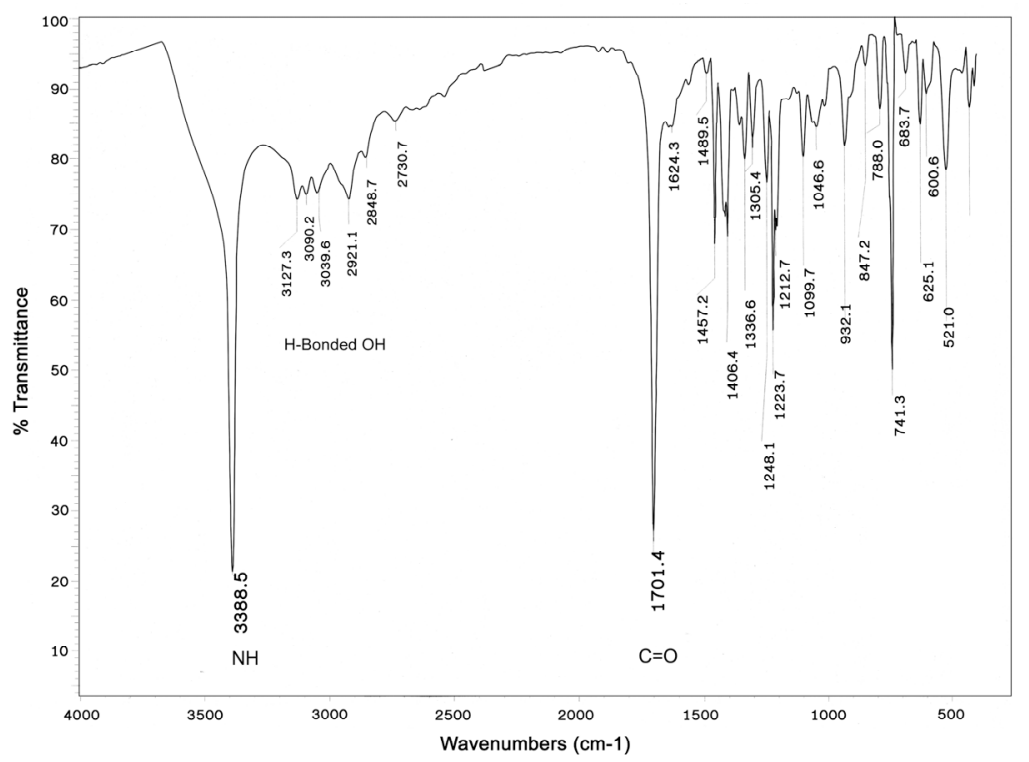

Appendix Fig. (1). 


\section{REFERENCES}

[1] Reddy, K.B. Kinetics and mechanism of oxidation of oxalate and molonate by diperiodatocuprate(III). Trans. Met. Chem., 1990, 15, 9-11.

[2] Sethuram, B. Some Aspects of Electron Transfer Reactions Involving Organic Molecules. Allied Publishers (P) Ltd: New Delhi, 2003

[3] Mahadevappa, D.S.; Rangappa, K.S.; Gowda, N.N.M.; Thimmegowda, B. Kinetic and mechanistic studies of oxidation of arginine, histidine and threonine in alkaline medium by N-chloroN-sodo-p-toluenesulfonamide. Int. J. Chem. Kinet., 1982, 14, 11831197.

[4] Mahanti, M.K.; Laloo, D. Kinetics of oxidation of amino acids by alkaline hexacynoferrate(III). J. Chem. Soc. Dalton Trans., 1990, 311-314.

[5] Kulkarni, R.M.; Bilehal, D.C.; Nandibewoor, S.T. Deamination and decarboxylation in the chromium catalysed oxidation of L-valine by alkaline permanganate and analysis of chromium(III) in microscopic amounts by a kinetic method. Trans. Met. Chem., 2003, 28, 199-208.

[6] Adari, K.K.; Nowduri, A.; Parvataneni, V. Kinetics and mechanism of oxidation of L-cystine by cerium(IV) in sulphuric acid medium. Acta Chim. Slov., 2008, 55, 425-429.

[7] Das, A.K. Kinetic and mechanistic aspects of metal ion catalysts in cerium(IV) oxidation. Coord. Chem. Rev., 2001, 213, 307-325.

[8] Shivananda, K.N.; Lakshmi, B.; Jagdeesh, R.V.; Puttaswamy Mahendra, K.N. Mechanistic study on the Ru(III)-catalysed oxidation of some aromatic primary diamines by chloramine- $\mathrm{T}$ in hydrochloric acid medium: a kinetic approach. Appl. Catal. A Gen., 2007, 326(2), 202-212.

[9] Tandon, P.K.; Mehrotra, A.; Shrivastava, M.; Dhusia, M.; Singh S.B. $\mathrm{Ru}(\mathrm{III})$ catalysis in the reaction of hexacynoferrate(III) and iodide ions in perchloric acid medium. Trans. Met Chem., 2007, 32, 991-999.

[10] Singh, A.K.; Srivastava, S.; Srivastava, J.; Srivastava, R.; Singh, P. Studies in kinetics and mechanism of oxidation of d-glucose and dfructose by alkaline solution of potassium iodate in the presence of $\mathrm{Ru}(\mathrm{III})$ as homogeneous catalyst. J. Mol. Catal. A Chem., 2007, $278,72-81$.

[11] Shetti, N.P.; Nandibewoor, S.T. Kinetic and mechanistic investigations on oxidations of L-tryptophan by diperiodatocuprate(III) in aqueous alkaline medium. Z. Phys. Chem., 2009, 223, 299-317.

[12] Hiremath, D.C.; Kiran, T.S.; Nandibewoor, S.T. Osmium(VIII)/ ruthenium(III)-catalysed oxidation of L-lysine by diperiodatocuprate(III) in aqueous alkaline medium- a comparative mechanistic approach by stopped flow technique. Catal. Lett., 2008, 122, 144-154.

[13] Reddy, C.S.; Vijay Kumar, T. Kinetic and mechanistic study of ruthenium(III) catalysed and uncatalysed oxidation of oxalic acid by acid bromate. Indian J. Chem., 1995, 34(A), 615-620.

[14] Murthy, C.P.; Sethuram, B.; Navaneeth, Rao. Kinetics of oxidations of some alcohols by diperiodatocuprate(III) in alkaline medium. T. Z. Phys. Chem., 1981, 262, 252-258.
[15] Jeffery, G.H.; Bassett, J.; Mendham, J.; Denny, R.C. Vogel's Textbook of Quantitative Chemical Analysis. $5^{\text {th }}$ ed. ELBS, Longman: Essex, UK, 1996, p. 455.

[16] Panigrahi, G.P.; Misro, P.K. Kinetics and mechanism of oxidation of aliphatic ketones by sodium metaperiodate: a comparative study of uncatalysed versus osmium tetraoxide- catalysed oxidation. Indian J. Chem., 1978, 16(A) 762-766.

[17] Randrerath, K. Thin layer chromatography. Academic press: New York, 1968, p. 101.

[18] Jagdeesh, R.V.; Puttaswamy. Ru(III), Os(VIII), Pd(II) \& Pt(IV) catalysed oxidation of glycyl-glycine by sodium N-chloro-ptoluenesulfonamide: comparative mechanistic aspects and kinetic modeling. J. Phy. Org. Chem., 2008, 21, 844-858.

[19] Moelwyn-Hughes, E.A. Kinetics of reactions in solutions, Oxford University Press: London, 1947, p. 297.

[20] Reddy, K.B.; Sethuram, B.; Navneeth, R.T. Oxidation of 1,2 ethanediol, 1,2-propanediol and 1,2-butanediol by diperiodatocuprate(III) in aqueous alkaline medium: a kinetic study. Z. Phys. Chem., 1987, 268(4), 706-710.

[21] Bailar, J.C. Jr.; Emelens, H.J.; Nyholm, S.R.; Trotman-Dikenson, A.F. Comprehensive inorganic chemistry, Pergamon Press: Oxford, 1975, Vol. 2, p. 1456.

[22] Niu, W.; Zhu, Y.; Hu, K.; Tong, C.; Yang, H. Kinetics of oxidation of SCN- by Diperiodatocuprate(III) DPC in alkaline medium. Int. J. Chem. Kinet., 1996, 28, 899-904.

[23] Jose, T.; Tuwar, S.M. Oxidation of threonine by the analytical reagent dieriodatocuprate(III) an autocatalysed reaction. J. Mol. Struct., 2007, 827(1), 137-144.

[24] Connick, R.E.; Fine, D.A. Ruthenium(III) chloride complexes: $\mathrm{RuCl}_{2}{ }^{+}$.J. Am. Chem. Soc., 1960, 82, 4187-1991.

[25] Cotton, F.A.; Wilkinson, G.; Murillo, C.A.; Bochmann, M. Advanced inorganic chemistry, $6^{\text {th }}$ ed. John Wiley and Sons Inc.: New York, 1999.

[26] Chang, R. Physical chemistry with applications to biological systems. Mcmillan: New York, 1981.

[27] Vinod, K.N.; Puttaswamy; Ninge G.K.N. Oxidative decolorisation of triphenylmethane dyes by Chloramine-T in alkaline medium catalysed by $\operatorname{Pd}(\mathrm{II})$ : a comparative spectrophotometric kinetic and mechanistic approach. J. Mol. Catal. A Gen., 2009, 298, 60-68.

[28] Rangappa, K.S.; Ragavendra, M.P.; Mahadevappa, D.S.; Channegouda, D. Sodium N-chlorobenzenesulfonamide as a selective oxidant for hexosamines in alkaline medium: A kinetic and mechanistic study. J. Org. Chem., 1998, 63, 531-536.

[29] Weissberger, A. In: Lewis, E.S. Ed., Investigation of rates and mechanism of reactions in techniques of chemistry, Wiley: New York, 1974, Vol. 4, p. 421.

[30] Farokhi, S.A.; Nandibewoor, S.T. Kinetic, mechanistic and spectral studies for the oxidation of sulfanilic acid by alkaline hexacynoferrate(III). Tetrahedron, 2003, 59, 7595-7602.

[31] Kiran, T.S.; Hiremath, C.V.; Nandibewoor, S.T. Kinetic, mechanistic and spectral investigations of ruthenium(III)/ osmium(VIII) catalysed oxidation of paracetamol by alkaline Diperiodatoargentate(III) (Stopped flow technique). Appl. Catal. A General, 2006, 305, 79-89. 